\title{
Multiagent imaging of the brain
}

\author{
Andrea Ciarmiello $\cdot$ Chiara Gaeta \\ Claudio Guidotti $\cdot$ Massimo del Sette
}

Received: 28 June 2013/ Accepted: 17 November 2013/Published online: 4 December 2013

(c) Italian Association of Nuclear Medicine and Molecular Imaging 2013

\begin{abstract}
Positron emission tomography (PET) and single-photon emission computed tomography (SPECT) are in vivo imaging techniques that, using a wide range of tracers, allow the non-invasive tracking of pathophysiological processes in healthy and diseased brain. One of most promising of the various PET and SPECT applications is the investigation of pathophysiological aspects of neurodegenerative disorders. This is an extremely important area of investigation given the aging of the global population and the high prevalence of brain disorders such as Alzheimer's disease and Parkinson's disease in elderly persons. Clinical translation of advances in molecular imaging research into clinical practice may, by overcoming the limitations of a diagnostic approach that relies exclusively on clinical judgment and structural imaging, lead to better clinical management of affected patients.
\end{abstract}

Keywords Brain - Neurodegenerative diseases .

Molecular imaging $\cdot$ PET $\cdot$ SPECT $\cdot$ PET/MRI

\section{Introduction}

Positron emission tomography (PET) and single-photon emission computed tomography (SPECT) are in vivo

Color figures online at http://link.springer.com/article/10.1007/ s40336-013-0042-y.

\section{A. Ciarmiello $(\bowtie) \cdot$ C. Gaeta $\cdot$ C. Guidotti}

Department of Nuclear Medicine, S. Andrea Hospital, Via

Vittorio Veneto, 197, La Spezia, Italy

e-mail: andrea.ciarmiello@asl5.liguria.it

M. del Sette

Neurology Department, S. Andrea Hospital, La Spezia, Italy imaging techniques that allow the non-invasive tracking of pathophysiological processes in healthy and diseased brain. The unique feature of in vivo emission tomography techniques is their potential for allowing integration of information about neuronal function, viability, neurotransmission systems, along with protein deposition and immune system activation. This integration of data about cerebral (dys)functions at cellular and molecular level is possible using a multiagent imaging approach.

Indeed, the use of an imaging approach that exploits the wide range of radiotracers developed in recent decades will likely lead to a better understanding of the pathophysiology of brain disorders, of their natural course, and consequently of their possible treatments.

In research settings, PET and SPECT radiotracers have been successfully used in drug development, for further understanding of the mechanism of action of pharmacological agents in the central nervous system [1]. In daily clinical practice, combining different tracers and techniques in sequential imaging sessions constitutes the current diagnostic workup for several brain diseases.

One of most promising of the various PET and SPECT applications is the investigation of pathophysiological aspects of neurodegenerative disorders. This is an extremely important area of investigation given the aging of the global population and the high prevalence of brain disorders such as Alzheimer's disease (AD) and Parkinson's disease (PD) in elderly life.

This review will focus on the perspectives for PET and SPECT radiotracers capable of mapping intracellular and extracellular mechanisms underlying several brain disorders that have a particularly high impact both on individuals and on society. Our discussion will deal mainly with neurodegenerative disorders. 


\section{Dementias}

Dementia is a term used to refer to a variety of neurodegenerative disorders associated with considerable disability and high costs to individuals and society [2]. The most common neurodegenerative disorders responsible for dementia, such as AD, dementia with Lewy bodies (DLB) and frontotemporal dementia (FTD), have different underlying pathogenetic mechanisms; each is associated with a distinctive course and its own set of possible complications [3].

A diagnosis of dementia is currently made in terms of probability and is based on clinical features as well as on the results of structural brain imaging investigations [computed tomography (CT) or magnetic resonance imaging (MRI)] and blood tests [4, 5].

However, the accuracy of these diagnostic criteria is limited compared with post-mortem histopathology [6].

Even though symptomatic medications are the only treatments currently available, an accurate diagnosis of dementia is critically important to avoid inappropriate interventions and to provide guidance for appropriate nonpharmacological management.

The recent introduction, in both investigational and clinical settings, of imaging biomarkers as an optional tool for $\mathrm{AD}$ diagnosis represents a cultural shift towards a more biologically focused workup in dementia [7, 8]. Clinical translation of the advances in molecular imaging research may, by allowing more accurate diagnosis of dementia, lead to better clinical management of affected patients. Moreover, such biomarkers may also make it possible to achieve early etiological characterization of the prodromal stage of dementia, also known as mild cognitive impairment (MCI) [9]. This is a particularly important aspect, given that the disease-modifying drugs currently under development are expected to be more effective in the early disease phase [10].

Neuronal damage or dysfunction and specific pathological features of dementias are the targets of the most widely validated PET biomarkers [11].

Neurodegeneration assessed using $\left[{ }^{18} \mathrm{~F}\right] \mathrm{FDG}$ PET has been extensively evaluated in dementia patients [12]. In fact, the cerebral metabolic rate of glucose (CMRglc) reflects synaptic activity and density [13]. Metabolic deficits in $\mathrm{AD}$ patients are present in the neocortical association areas, with reductions detected predominantly in temporoparietal regions, the posterior cingulate cortex and the frontal cortex [14] (Fig. 1). Metabolic reductions in the medial occipital cortex are typically observed in DLB, whereas metabolic impairments in FTD typically involve frontal or frontotemporal regions [15] (Fig. 1). [ $\left.{ }^{18} \mathrm{~F}\right] \mathrm{FDG}$ PET has been shown to correctly differentiate AD subjects from healthy controls with high sensitivity and specificity, using either clinical assessment or pathological confirmation as reference standard [16-20]. In addition, despite some overlap in the hypometabolic patterns, several studies have proved the feasibility of using $\left[{ }^{18} \mathrm{~F}\right] \mathrm{FDG}$ PET in the differential diagnosis of the major neurodegenerative disorders, the technique being found to show higher diagnostic accuracy than clinical judgment [21].

The added value of $\left[{ }^{18} \mathrm{~F}\right] \mathrm{FDG}$ PET over the clinical assessment of patients suspected of having AD was shown by Jagust et al. [22]. The probability of detecting postmortem AD pathology increases from 70 to $84 \%$ in a patient with a positive PET scan, whereas it decreases to $31 \%$ in the presence of a negative scan. Conversely, a negative clinical evaluation for $\mathrm{AD}$ is associated with a $35 \%$ probability of post-mortem pathology, versus $70 \%$ in the case of a positive $\left[{ }^{18} \mathrm{~F}\right] \mathrm{FDG}$ PET scan.

CMRglc reductions in patients with MCI predict progression to $\mathrm{AD}$ with high accuracy [23, 24] and have been found to be highly correlated with the severity of the clinical impairment [25]. Even though the hypometabolic pattern in patients with DLB can be similar to that observed in $\mathrm{AD}$, the involvement of the occipital cortices is usually more severe while the temporal lobes are less affected [26].

$\beta$-amyloid $(A \beta)$ plaques are present in the cortical gray matter in all cases of AD, in 50-70\% of patients with DLB, and in normal elderly people in a percentage that increases with age [27]. Since the advent of the first amyloid tracer, ${ }^{11} \mathrm{C}$-labeled Pittsburgh compound B (PiB) [27], several studies have been published assessing the amyloid status of individuals with dementia.

In the attempt to overcome the limitations related to the short half-life of ${ }^{11} \mathrm{C}$ (20 min), ${ }^{18} \mathrm{~F}$-labeled $\mathrm{A} \beta$ radiopharmaceuticals have been developed, including ${ }^{18} \mathrm{~F}-3^{\prime}-\mathrm{F}-\mathrm{PiB}$ (flutemetamol), ${ }^{18} \mathrm{~F}-\mathrm{AV}-45$ (florbetapir), ${ }^{18} \mathrm{~F}-\mathrm{AV}-1$ or ${ }^{18} \mathrm{~F}$ BAY94-9172 (florbetaben), and ${ }^{18}$ F-AZD4694 or NAV4694. A high correlation between PiB and ${ }^{18}$ F-labeled ligands has been demonstrated [27], supporting the translation of PiB PET findings into the domain of ${ }^{18} \mathrm{~F}$-labeled radiopharmaceuticals [28].

$\mathrm{PiB}$ PET studies have shown a robust difference in $\mathrm{PiB}$ uptake between $\mathrm{AD}$ patients and age-matched controls, reporting very high sensitivity $(90 \%)$ and high negative predictive value. On the other hand, specificity and positive predictive value decline with age, showing a diagnostic accuracy for AD of 75-80 \% in patients over 80 years of age [11]. However, if the purpose of the diagnostic assessment is to evaluate the presence of $A \beta$ plaques, the accuracy of amyloid imaging remains high at all ages [27]. A positive amyloid PET does not establish a diagnosis of $\mathrm{AD}$, but it can help to support or exclude the presence of $\mathrm{AD}$ in the context of a more comprehensive evaluation of the patient [28]. 

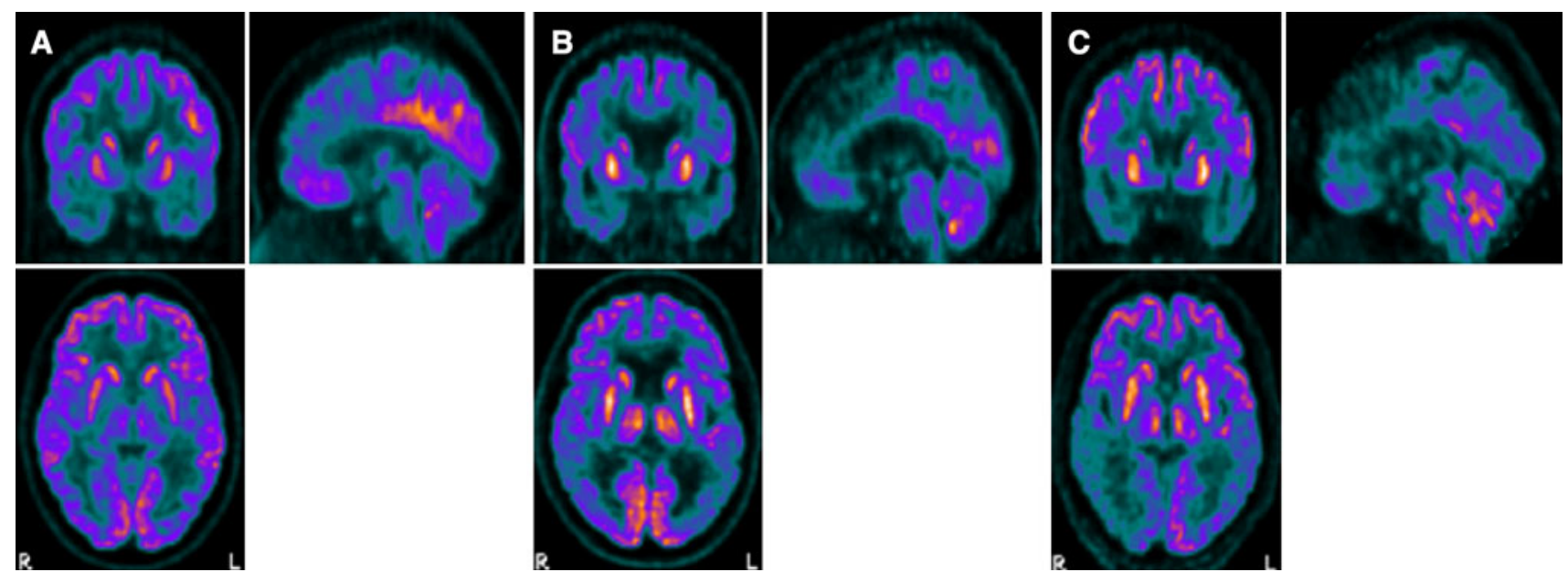

Fig. 1 Images showing normal $\left[{ }^{18} \mathrm{~F}\right] \mathrm{FDG}$ distribution in a healthy subject (a), and reduced uptake in posterior brain areas in an MCI subject (b) and a DLB subject (c). This reduced uptake is particularly evident in the occipital areas of the DLB patient (color figure online)

An important clinical application of amyloid PET is the differential diagnosis between $\mathrm{AD}$ and FTD, as $\mathrm{A} \beta$ pathology is not present in the latter. In a recent study [29] that included $62 \mathrm{AD}$ patients and 45 FTD patients, PiB and $\left[{ }^{18}\right.$ F]FDG PET showed similar diagnostic accuracy. However, PiB was more sensitive and showed higher inter-rater reliability and agreement between qualitative and quantitative evaluation.

Since the publication of the amyloid cascade hypothesis [30], according to which accumulation of $\mathrm{A} \beta$ during early stages of the disease precedes a cascade of neuropathological events that eventually lead to $\mathrm{AD}$, intense efforts have been directed at evaluating the possible role of amyloid imaging in the prognostic assessment of MCI patients and cognitively normal elderly people. Even though several studies support the notion that many healthy elderly people with a positive PiB PET are in a preclinical phase of $\mathrm{AD}$, this hypothesis requires further longitudinal investigation [31]. On the other hand, current data suggest that amyloid PET may correctly stratify MCI patients, detecting those who will convert to $\mathrm{AD}$ [32]. Forsberg et al. [33] showed that the mean cortical PiB retention in MCI patients was intermediate compared with the value recorded in healthy controls and AD patients. MCI patients who converted to $\mathrm{AD}$ during follow-up compared to non-converting patients had a significantly higher $\mathrm{PiB}$ retention, comparable to that of $\mathrm{AD}$ patients.

The findings of several longitudinal studies, which set out to compare $\mathrm{PiB}$ retention, $\left[{ }^{18} \mathrm{~F}\right] \mathrm{FDG}$ uptake and $\operatorname{cog}$ nitive impairment in $\mathrm{AD}$ and $\mathrm{MCI}$ patients, suggest a bidirectional interrelationship between neurodegeneration assessed by $\left[{ }^{18} \mathrm{~F}\right] \mathrm{FDG}$ PET and $\mathrm{A} \beta$ deposition evaluated by PiB PET [34]. Amyloid-positive regions show maintenance of neuronal activity in an early preclinical phase, followed by progressive neuronal degeneration coupled with cognitive decline. In addition, while neuronal degeneration and cognitive impairment continue in $\mathrm{AD}$ patients, the accumulation of $A \beta$ appears to be stable. Thus, whereas $\mathrm{PiB}$ studies show inverse correlations with glucose hypometabolism in some brain regions in $\mathrm{AD}$ patients, no significant correlations are observed in MCI patients. Accordingly, PiB PET does not correlate with cognitive impairment in $\mathrm{AD}$ patients, whereas this correlation is observed in MCI patients [27]. In conclusion, whereas $\left[{ }^{18}\right.$ F]FDG PET can be used to determine the degree and progression of neurodegeneration [35], amyloid PET appears to be a powerful tool for the early diagnosis of $\mathrm{AD}$ pathology that may lead to a greater level of diagnostic confidence in particular cases, such as MCI patients, patients with possible $\mathrm{AD}$ and atypical clinical presentation, or patients with atypically young-onset dementia [28].

In DLB, amyloid deposits are associated with AD-like atrophy, predominantly involving the parahippocampal area and lateral temporal and parietal cortices [36]. In a study comparing DLB patients with patients affected by Parkinson's disease dementia (PDD), the presence of amyloid plaques in the DLB patients was found to be linked to the cognitive impairment and to the timing of the onset of dementia symptoms relative to parkinsonism [37].

Neurofibrillary tangles (NFTs) result from the abnormal aggregation of tau protein and can be regarded as another pathological hallmark of AD [38]. Among several probes developed to detect tau pathology in the brain, the radiotracer FDDNP (i.e., 2-(1- \{6-[(2-[ $\left[{ }^{18} \mathrm{~F}\right]$ fluoroethyl)(methyl)amino $]-2-$ naphthyl $\}$ ethylidene)malononitrile) has been shown to label senile plaques and NFTs in vitro [39]. PET with FDDNP has proved able to distinguish between cognitively normal, $\mathrm{MCI}$ and $\mathrm{AD}$ subjects [40]. More recently, FDDNP has been proposed as a feasible diagnostic tool for stratifying nondemented subjects with different levels of dementia risk [41]. 
Inflammatory mechanisms, like microglial activation, are thought be involved in the pathogenesis of AD. Furthermore, pathological and animal studies have demonstrated that microglia are attracted to sites of amyloid deposition. However, the first in vivo assessments of microglial activation using PET and ${ }^{11}$ C-PK11195 (a marker of translocator protein) in AD and DLB have given discordant results. Okello et al. [42] showed increased binding of ${ }^{11} \mathrm{C}$-PK11195 in the frontal cortex in a small group of PiB-positive versus PiB-negative MCI patients. Neuroinflammation was also reported in DLB patients compared with controls [43]. Conversely, a more recent study comparing patients with probable $\mathrm{AD}, \mathrm{MCI}$ patients and healthy controls did not demonstrate significant differences in uptake between the groups [44]. Larger studies and a better understanding of the role of inflammation in dementia are needed to draw definite conclusions.

Neurotransmitter systems (i.e. the cholinergic, dopaminergic, GABAergic and serotonergic systems) are impaired in dementia. A wide range of PET and SPECT radiotracers is available for studying the integrity of these systems.

Over the years, several SPECT and PET studies using $\left[{ }^{123} I\right] I B V M \quad\left(\left[{ }^{123} I\right]\right.$ iodobenzovesamicol$)$, a pre-synaptic ligand for the acetylcholine (ACh) vesicular transporter, and $\left[{ }^{11} \mathrm{C}\right] \mathrm{MP} 4 \mathrm{~A}\left(\mathrm{~N}-\left[{ }^{11} \mathrm{C}\right]\right.$ methylpiperidin-4-yl acetate), an $\mathrm{ACh}$ analog whose trapping in the brain is directly proportional to the presence of acetylcholinesterase (AChE), have demonstrated the occurrence of a cortical pre-synaptic cholinergic decline mainly in severe-moderate $\mathrm{AD}$ and in early-onset cases of $\mathrm{AD}[45,46]$. A marked reduction in cortical AChE was demonstrated using PET with $\left[{ }^{11} \mathrm{C}\right] \mathrm{MP} 4 \mathrm{~A}$ in patients with DLB, in whom the phenomenon was found to be more severe than in AD patients [47].

The density of pre-synaptic membrane dopamine transporters (DATs) and of dopamine terminal vesicular monoamine transporters can be assessed using various SPECT/PET radiotracers. DAT imaging with ${ }^{123}$ I-FP-CIT SPECT is useful for diagnosing DLB and exhibits sufficient diagnostic accuracy to distinguish DLB from AD [48]. An abnormal DAT scan in a patient with a clinical suspicion of DLB or other dementia shows a diagnostic sensitivity of $83 \%$ and specificity of $100 \%$ for autopsyconfirmed DLB [49].

Recently, a combined PET imaging approach with ${ }^{11} \mathrm{C}$ dihydrotetrazine, a striatal vesicular monoamine transporter marker, and PiB has been proposed as diagnostic stratification tool to aid in differential diagnosis of AD, DLB and FTD [50]. Alterations in the GABAergic system can be evaluated assessing the availability of GABA receptors using ${ }^{11} \mathrm{C}$ flumazenil PET or ${ }^{123}$ I-iomazenil SPECT. Even though cortical depletion of GABA receptors has been proven by post-mortem studies in $\mathrm{AD}$, in vivo imaging studies with PET or SPECT provided discordant results [51, 52].
Brain perfusion imaging with the two most commonly employed SPECT tracers, ${ }^{99 \mathrm{~m}} \mathrm{Tc}$-hexamethylpropylenamine (HMPAO) and ${ }^{99 \mathrm{~m}} \mathrm{Tc}$-ethylcysteinate dimmer (ECD), has been extensively used in the diagnosis, therapeutic management and follow-up of dementia patients [53]. In the absence of cerebrovascular disease, hypoperfusion is related to impaired neuronal activity and is coupled with decreased metabolism detected by $\left[{ }^{18} \mathrm{~F}\right]$ FDG PET, showing similar patterns of reduced regional uptake in different types of dementia. However, correlations of abnormal tracer uptake between $\left[{ }^{18} \mathrm{~F}\right] \mathrm{FDG}$ PET and HMPAO SPECT in the same subjects are only modest $(r=0.43)$, with the best correspondence being found in the temporoparietal and posterior cingulate association cortices [54]. $\left[{ }^{18} \mathrm{~F}\right] \mathrm{FDG}$ PET performs better in discriminating between AD patients and controls, showing a sensitivity of $100 \%$ compared to the $90 \%$ of SPECT [55].

Thus, when it is possible to choose between PET and SPECT, PET should be preferred. Nevertheless, SPECT can be considered a reliable alternative.

\section{Movement disorders}

PD is a progressive neurodegenerative disease clinically characterized by rigidity, rest tremors and bradykinesia associated with the loss of dopaminergic neurons in the substantia nigra pars compacta and a subsequent striatal dopaminergic deficiency [56]. Even though the U.K. Parkinson's Disease Society Brain Bank diagnostic criteria have improved the accuracy of clinical diagnosis of PD, anatomical-pathological studies nevertheless show a high rate of misdiagnosis (25\%) [57]. Furthermore, when diagnosis is based entirely on clinical criteria, treatment may be delayed for years until functional disability appears. Molecular imaging with SPECT or PET allows a more accurate diagnostic workup and can be used for the differential diagnosis between PD and parkinsonian syndromes (also known as Parkinson-plus syndromes) such as multiple system atrophy (MSA), progressive supranuclear palsy (PSP), corticobasal degeneration (CBD) and diffuse Lewy body disease (DLBD).

The availability of pre-synaptic DATs can be assessed using a variety of SPECT and PET tracers, including ${ }^{123}$ I$\beta$-CIT, ${ }^{123}$ I-FP-CIT (DaTSCAN), ${ }^{123}$ I-altropane, ${ }^{99 \mathrm{~m}} \mathrm{Tc}$ TRODAT- 1 and ${ }^{11} \mathrm{C}$-CFT $\left(\left[{ }^{11} \mathrm{C}\right] 2 \beta\right.$-carbomethoxy-3 $\beta$ - $(4-$ fluorophenyl)tropane) [58]. Other pre-synaptic PET tracers such as ${ }^{18} \mathrm{~F}$-DOPA and ${ }^{11} \mathrm{C}$ - or ${ }^{18} \mathrm{~F}$-dihydrotetrabenazine (DTBZ) are markers, respectively, of terminal DOPA aromatic acid decarboxylase activity (AADC) and of type 2 vesicle monoamine transporter availability [59].

Over the years, various studies using SPECT with ${ }^{123}$ I-bCIT and ${ }^{123}$ I-FP-CIT showed a clear reduction of striatal 

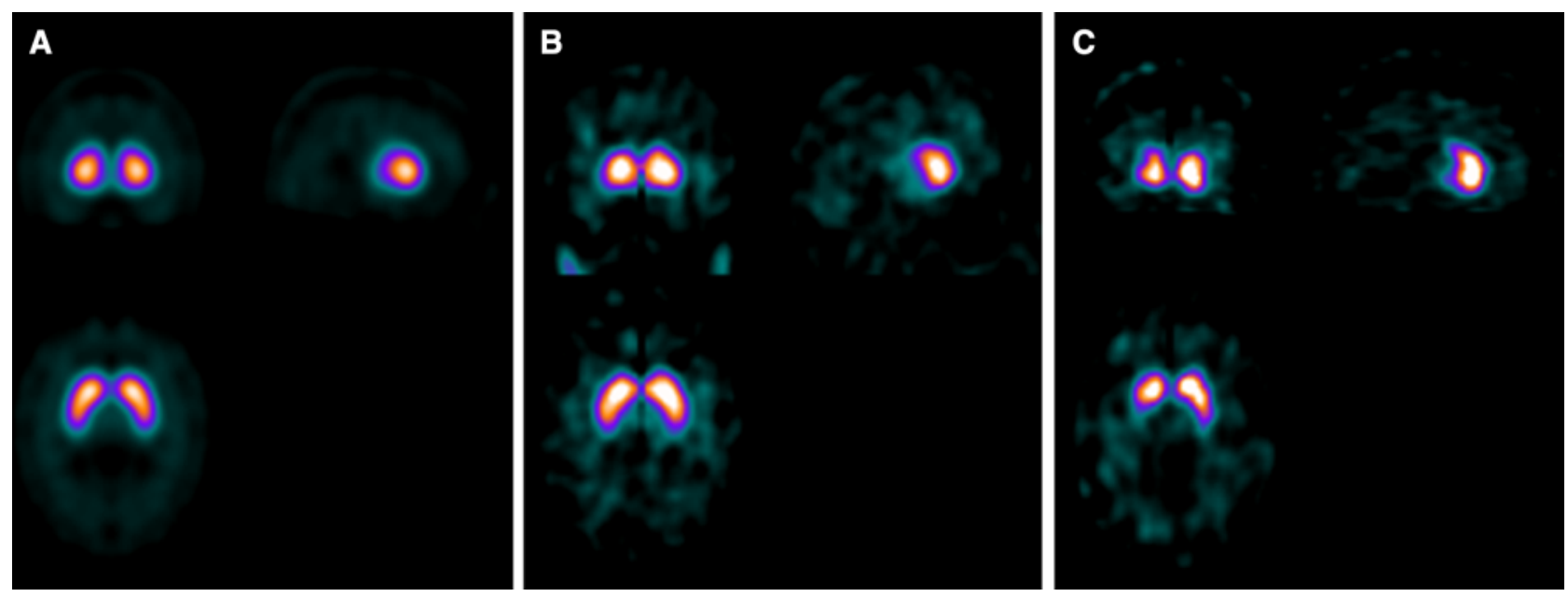

Fig. 2 Normal distribution of ${ }^{123}$ I-FP-CIT (DaTSCAN) in a healthy subject (a) and in an essential tremor subject (b). In a PD patient (c), the right putamen shows a reduced concentration of radiotracer (color figure online)

DATs in patients with PD [60, 61]. Differential diagnosis between PD and other parkinsonian syndromes from those with essential tremor or other neurological diseases which do not involve the nigrostriatal dopaminergic system can be particularly challenging when based exclusively on clinical features. Compared with clinical assessment, ${ }^{123}$ I-FP-CIT SPECT was found to show higher specificity in differentiating between PD and essential tremor [61] (Fig. 2). The impact on clinical management can be considered one of the most direct measures of the benefit derived from a diagnostic imaging modality. The results of two studies including patients with clinically uncertain parkinsonism syndromes have shown that including a measure of striatal dopaminergic function in the workup of uncertain parkinsonism cases helps in planning their management. In fact, when ${ }^{123}$ I-FP-CIT SPECT findings were divulged to clinicians, the diagnosis of parkinsonian syndrome was revised in $52 \%$ of the 118 patients and the management strategy was changed in $72 \%$ [62]. Also, ${ }^{123}$ I-FP-CIT SPECT was found to have a high negative predictive value. Only $3 \%$ of 150 patients suspected of having a parkinsonian syndrome but presenting normal dopamine terminal function on SPECT showed clinical progression during 2 years of follow-up [63]. DAT imaging may be useful in identifying individuals with early PD (i.e. before onset of symptoms) showing a relative reduction in uptake in the putamen compared with the caudate [64].

Various studies have demonstrated the feasibility of using ${ }^{18} \mathrm{~F}$-DOPA PET to differentiate PD patients from healthy controls. Jokinen et al. [65] showed a lower striatal-to-occipital ratio in PD patients compared with controls, with the lowest ratio being found in the posterior putamen contralateral to the side of predominant clinical symptoms. However, because of up-regulation of AADC activity in the surviving cells, ${ }^{18} \mathrm{~F}$-DOPA may underestimate the severity of nigrostriatal loss, especially in the early stages of disease [66].

${ }^{11} \mathrm{C}$ - or ${ }^{18} \mathrm{~F}$-DTBZ uptake is decreased in the corpus striatum in PD patients compared with control subjects and it is not affected by synaptic dopamine levels or dopaminergic agents [67]. Thus, even though its use has, to date, been limited to research settings, DTBZ can be considered one of the best available ligands for examining dopaminergic system integrity [68].

As pre-synaptic dopaminergic nerve terminals are involved in most degenerative parkinsonian disorders, presynaptic dopaminergic imaging performs poorly in differentiating between PD and Parkinson-plus syndromes. Conversely, this differential diagnosis is possible using post-synaptic dopaminergic imaging assessing post-synaptic D2 receptor density with benzamide derivative ligands, such as ${ }^{11} \mathrm{C}$-raclopride and ${ }^{123} \mathrm{I}$-IBZM $\left({ }^{123} \mathrm{I}\right.$-iodobenzamide). In fact, various authors have shown reduced striatal binding of D2 receptor ligands in patients with Parkinson-plus syndromes and increased binding in untreated patients with early PD [69-71]. Even though international guidelines recommend post-synaptic imaging to distinguish PD from Parkinson-plus syndromes [69], a recent meta-analysis on the role of SPECT in parkinsonian syndromes indicated a low level of diagnostic accuracy in differentiating between PD and Parkinson-plus syndromes [72]. Furthermore, post-synaptic dopaminergic imaging does not discriminate among Parkinson-plus syndrome subgroups. For this reason, different tracer approaches have been proposed.

It has been demonstrated that $\left[{ }^{18} \mathrm{~F}\right] \mathrm{FDG}$ PET can reveal regional differences in glucose metabolism between PD and Parkinson-plus syndromes [73]. However, broad application of metabolic imaging in these neurodegenerative diseases has been limited on account of the substantial 
variability in brain activity between subjects and brain regions. To overcome these limitations, a "network" analysis approach was proposed, based on the assessment of functional interactions between brain regions [74]. The rationale for this approach was that neurodegenerative processes, even if highly localized, are associated with disease-specific alterations in functional connectivity across the whole brain. Applying this method of analysis, PD appears to be characterized by increased pallidothalamic and pontine metabolic activity and relative reductions in activity in the premotor cortex, supplemental motor area, and parietal association regions [75]. MSA shows metabolic decreases in the putamen and the cerebellum, whereas PSP shows metabolic decreases predominantly in the upper brainstem and medial prefrontal cortex, as well as in the medial thalamus, the caudate nuclei, the anterior cingulate area, and the superior frontal cortex. Asymmetrical decreases in FDG uptake in frontal and parietal cortices and subcortical regions have been reported in CBD patients, whereas DLBD is characterized by bilateral metabolic reduction in the occipital cortex [76].

Lewy bodies are constantly present in the sympathetic ganglia of PD and DLBD patients [77], leading to degeneration of adrenergic post-ganglionic pathways, a phenomenon that can be assessed using specific ligands targeting the adrenergic terminations at cardiac level. PET with ${ }^{11} \mathrm{C}$-MHED or ${ }^{18} \mathrm{~F}$-DOPA and SPECT with ${ }^{123} \mathrm{I}$ MIBG showed reduced cardiac uptake in PD and DLBD patients compared with patients with other Parkinson-plus syndromes [78, 79].

Microglial activation has been associated with loss of substantia nigra neurons in PD and appears to be widespread in the end stage of the disease, being detected histochemically in the basal ganglia, cingulate, hippocampus and cortical association areas [80]. PET studies in PD patients using ${ }^{11} \mathrm{C}-\mathrm{PK} 11195$ showed an increased midbrain uptake, inversely correlated with the uptake of ${ }^{11} \mathrm{C}-\mathrm{CFT}$. Other authors demonstrated increased ${ }^{11} \mathrm{CPK} 11195$ uptake in the medulla and pons, striatum, pallidum and frontal cortex, a pattern that reflects the distribution of Lewy body pathology [81]. The results of a 2-year follow-up study of PD patients suggest that microglial activation does not change during the disease course, even in the presence of a clinical deterioration [81]. These findings suggest that early treatment with neuroprotective drugs to suppress microglial activation could have favorable effects in PD patients. In MSA, significant ${ }^{11} \mathrm{C}$-PK11195 uptake was observed in the putamen, pallidum, pons, substantia nigra pars compacta, and dorsolateral prefrontal cortex, in topographic correspondence with the distribution of neuropathological alterations [82]. In PSP patients, ${ }^{11}$ C-PK11195 PET showed significant levels of activated microglia in the midbrain, cerebellum, pons, frontal lobe, and basal ganglia, while in CDB patients activated microglia were observed at the level of the caudate nucleus, putamen, substantia nigra pars compacta, pons, and pre- and postcentral gyrus [81, 83].

A significant number of PD patients develop either MCI or frank dementia, having a sixfold higher risk of developing dementia compared with healthy controls [84]. The pathological basis of dementia in PD is likely to be multifactorial. Possibilities include cortical Lewy body disease and concomitant $\mathrm{A} \beta$ plaque deposition, among others. It is still unclear whether PDD and DLB are part of a spectrum or separate disease entities [84]. DLB is clinically distinguished from PDD purely based on the different timing of onset of dementia symptoms in the two conditions. Histopathology analyses show that cortical $A \beta$ deposition can be found in PDD, albeit less frequently than in DLB [85]. Several studies using ${ }^{11} \mathrm{C}$-PiB PET to compare DLB, PDD and PD without dementia show an increased uptake in only a minority of PDD cases, in whom the pattern of distribution of $A \beta$ plaques is similar to that observed in DLB $[86,87]$. Even though findings regarding the association between $A \beta$ plaque load and cognitive decline in PDD and DLB are discordant, in vivo imaging markers of amyloid load may be able to identify those PDD and DLB subjects who can benefit from novel anti-amyloid strategies.

Huntington's disease (HD) is an autosomal dominant neurodegenerative disease caused by an expansion mutation of the $C A G$ gene over 35 trinucleotide repeats in the Huntington's gene on chromosome $4 \mathrm{p} 16.3$ [88, 89]. The number of CAG repeats is a major determinant of the age at onset of HD and other poly-(CAG) diseases. Symptoms are characterized by the triad of cognitive impairment, psychiatric disturbance and movement disorder. The pathology preferentially affects striatal areas and the caudate nucleus appears to be more severely affected than the putamen. The mechanism leading to neuronal death is not completely understood, but it is believed that abnormal huntingtin may be noxious to neurons through glutamate-mediated excitotoxicity [90]. Screening genetic tests allow identification of subjects at risk of the disease. All patients showing triplet abnormalities will eventually develop clinically evident disease. Age at onset of disease can be predicted using regression analysis based on the number of triplets. However, the penetrance of the genetic abnormality is variable and there is considerable variability in the age at onset of disease even in patients with similar number of triplets [91].

$\left[{ }^{18}\right.$ F]FDG PET studies in symptomatic HD patients revealed reduced striatal glucose metabolism. However, in the early symptomatic phases of HD, only caudate hypometabolism has been reliably identified, and putamen metabolism may be normal [92]. In symptomatic patients, as well as in presymptomatic (preHD) subjects that are 

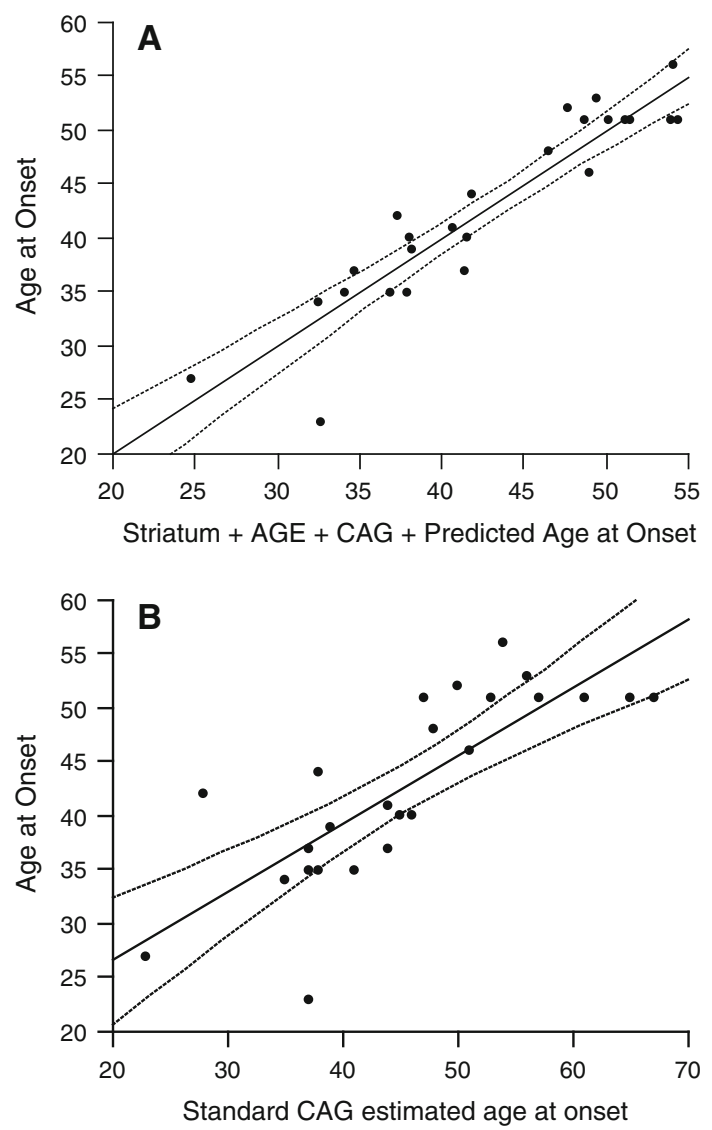

Fig. 3 Linear dependence of predicted age at onset on a CAG-based model and a multivariate model (CAG-based + striatum $\left[{ }^{18} \mathrm{~F}\right] \mathrm{FDG}$ uptake). Regression line and $95 \%$ confidence interval between true age at disease onset and estimated age at disease onset by the regression model including CAG expansion alone (a) and CAG expansion combined with glucose metabolism in the striatum (b) in 26 phenoconverted subjects. Regression equations were $y=14+$ $0.63 x, R^{2}=0.63, p<0.0001(\mathbf{a})$, and $y=-4.19 \mathrm{e}^{-13} \times 1 x, R^{2}=$ $0.86, p<0.0001(\mathbf{b})$

healthy carriers of the CAG mutation, a significant correlation was found between striatal metabolism and the estimated time to symptom onset (Fig. 3) [93, 94]. Interestingly, both in clinically unaffected subjects at risk of HD and in symptomatic patients, metabolic reductions were not only confined to the striatum but also involved the frontal cortex and the temporal lobes. The metabolic decline correlated linearly with the severity of motor symptoms calculated using the Unified Huntington Disease Rating Scale (UHDRS). Similarly, the rate of metabolic changes in the frontal and temporal areas of the cerebral cortex correlated linearly with worsening behavioral scores on UHDRS-III. Application of brain tissue segmentation techniques to PET data to correct for partial volume effect showed that metabolic reductions were not artifacts due to brain atrophy since CMRglu deficits remained significant even after partial volume correction. These results highlight that HD affects the cerebral cortex in addition to the striatum, and that the disease is associated with loss of white as well as of gray matter $[93,94]$.

Many studies showing early defects in cortical and striatal glucose metabolism [93, 95] have driven the search for sensitive brain markers (dry biomarkers) that might be measured before HD becomes manifest, thereby making it possible to predict how quickly overt symptoms are likely to appear in at-risk mutation carriers. Research models to date attempting to predict the age at onset in unaffected mutation carriers have merely sought to relate CAG expansion size to subject age [96]. Recently a new model for predicting the age at onset was reported: this model includes, along with CAG expansion and the subject's age, uptake of $\left[{ }^{18} \mathrm{~F}\right] \mathrm{FDG}$ on PET. The study group comprised 43 preHD subjects carrying the HD mutation. They underwent an $\left[{ }^{18} \mathrm{~F}\right]$ FDG PET scan and were prospectively followed up for at least 5 years using the UHDRS to detect clinical changes. The authors showed that caudate hypometabolism detected in the brains of HD subjects precedes early clinical phenoconversion. This new finding should help to improve prediction of age at onset in HD [97].

PET with $\left[{ }^{18} \mathrm{~F}\right] \mathrm{FDG}$ has been used for monitoring HD patients that are being treated with riluzole, a glutamate receptor antagonist that is thought to reduce excitotoxicity. Patients treated with riluzole showed significantly less gray matter volume loss and less severe CMRglc decreases in the striatum and in cortical areas. Moreover, plasma levels of brain-derived neurotrophic factor were significantly higher in patients treated with riluzole [94].

In a recent study by Politis et al., MRI and PET were combined to investigate the functional and structural changes of the brain in asymptomatic mutation carriers. Regional volume changes were studied using MRI volumetric analysis, whereas ${ }^{11} \mathrm{C}$-raclopride and ${ }^{11} \mathrm{C}$-PK11195 PET were used to investigate, respectively, the integrity of post-synaptic dopamine D2/D3 receptors and the presence of altered levels of activated microglia. The authors found reduced brain volume and reduced ${ }^{11} \mathrm{C}$-raclopride specific binding. Interestingly, significantly increased ${ }^{11}$ C-PK11195 uptake was found in sensorimotor and associative striatum of the preHD cases, leading the authors to conclude that activated microglia in brain areas related to cognitive function may be a predictor of clinical onset [98].

In vitro studies showed that neuronal loss in HD is associated with derangements in many neurotransmitter systems. The role of dopamine in the clinical manifestations of HD has been a topic of particular interest given the prominence of the movement disorder in this condition. Changes in the dopaminergic system have been assessed in HD patients using PET. Striatal binding correlated negatively with disease stage and positively with the MiniMental State Examination score. Both $\mathrm{D}_{1}$ and $\mathrm{D}_{2}$ receptor 
binding were significantly reduced in the moderateadvanced patients and in the mutation carriers [99]. Patients with more rigidity showed greater receptor loss than patients without significant rigidity [100]. A decrease in $D_{1}$ and $D_{2}$ receptors has also been reported in asymptomatic mutation carriers [101].

Another area of interest is the gabaergic system. The vast majority $(>90 \%)$ of striatal neurons are gabaergic. Abnormalities in the gabaergic system were investigated using PET and ${ }^{11} \mathrm{C}$-flumazenil, an antagonist of the central benzodiazepine receptor [102]. It was found that benzodiazepine receptor density was significantly decreased in the caudate nucleus of HD patients compared with controls. This abnormality was restricted to the striatum even though glucose metabolism was significantly reduced not only in the caudate nucleus but also in the putamen and thalamus [102].

\section{Molecular neuroimaging with PET/MRI}

PET/MRI is a new hybrid imaging technology which is attracting growing interest in the medical community because of its potential clinical and research applications. The availability of new MRI techniques and sequences such as MR spectroscopy, diffusion-weighted imaging (DWI), dynamic contrast-enhanced MRI (DCE-MRI) and blood oxygen level-dependent (BOLD) fMRI has broadened the diagnostic spectrum of MRI beyond anatomical morphological imaging of the brain. Indeed, MR spectroscopy provides a measure of biochemicals in tissue, DWI assesses cellular density, tissue architecture and extracellular space tortuosity, DCE-MRI describes vessel density, vascular permeability and tissue perfusion, while BOLD fMRI evaluates changes in blood oxygen levels.

By providing co-registered functional PET and anatomical/functional MR images, PET/MRI opens up exciting possibilities for the evaluation of brain diseases. All the new MRI techniques and sequences can potentially be used in combination with the molecular information provided by PET [103].

\section{Conclusion}

Currently, several tracers for PET and SPECT imaging are widely used in the diagnostic workup of patients with brain diseases. Many other tracers have recently been developed and may lead to better clinical management of patients, overcoming the limitations of a diagnostic approach that relies exclusively on clinical judgment and structural imaging. Molecular imaging, providing a better understanding of pathophysiological processes underlying these disorders, opens up exciting new possibilities for the development of treatments aimed at modifying the natural course of different brain diseases.

Conflict of interest The authors of the manuscript-Andrea Ciarmiello, Chiara Gaeta, Claudio Guidotti and Massimo del Settedeclare no conflict of interest.

Compliance with ethics guidelines This article does not contain any study with human or animal subjects performed by any of the authors.

\section{References}

1. Willmann JK, van Bruggen N, Dinkelborg LM, Gambhir SS (2008) Molecular imaging in drug development. Nat Rev Drug Discov 7:591-607

2. Olesen J, Gustavsson A, Svensson M, Wittchen HU, Jönsson B (2012) The economic cost of brain disorders in Europe. Eur J Neurol 19:155-162

3. Salloway S (2012) Clinical and pathological examples of Alzheimer's disease, dementia with Lewy bodies, and frontotemporal dementia. Med Health R I 95:207-209

4. McKeith IG, Galasko D, Kosaka K, Perry EK, Dickson DW, Hansen LA, Salmon DP, Lowe J, Mirra SS, Byrne EJ, Lennox G, Quinn NP, Edwardson JA, Ince PG, Bergeron C, Burns A, Miller BL, Lovestone S, Collerton D, Jansen EN, Ballard C, de Vos RA, Wilcock GK, Jellinger KA, Perry RH (1996) Consensus guidelines for the clinical and pathologic diagnosis of dementia with Lewy bodies (DLB): report of the consortium on DLB international workshop. Neurology 47:1113-1124

5. Neary D, Snowden JS, Gustafson L, Passant U, Stuss D, Black S, Freedman M, Kertesz A, Robert PH, Albert M, Boone K, Miller BL, Cummings J, Benson DF (1998) Frontotemporal lobar degeneration: a consensus on clinical diagnostic criteria. Neurology 51:1546-1554

6. Knopman DS, Boeve BF, Parisi JE, Dickson DW, Smith GE, Ivnik RJ, Josephs KA, Petersen RC (2005) Antemortem diagnosis of frontotemporal lobar degeneration. Ann Neurol $57: 480-488$

7. McKhann GM, Knopman DS, Chertkow H, Hyman BT, Jack CR Jr, Kawas CH, Klunk WE, Koroshetz WJ, Manly JJ, Mayeux R, Mohs RC, Morris JC, Rossor MN, Scheltens P, Carrillo MC, Thies B, Weintraub S, Phelps CH (2011) The diagnosis of dementia due to Alzheimer's disease: recommendations from the National Institute on Aging-Alzheimer's Association workgroups on diagnostic guidelines for Alzheimer's disease. Alzheimers Dement 7:263-269

8. Dubois B, Feldman HH, Jacova C, Dekosky ST, BarbergerGateau P, Cummings J, Delacourte A, Galasko D, Gauthier S, Jicha G, Meguro K, O’Brien J, Pasquier F, Robert P, Rossor M, Salloway S, Stern Y, Visser PJ, Scheltens P (2007) Research criteria for the diagnosis of Alzheimer's disease: revising the NINCDS-ADRDA criteria. Lancet Neurol 6:734-746

9. Gauthier S, Reisberg B, Zaudig M, Petersen RC, Ritchie K, Broich K, Belleville S, Brodaty H, Bennett D, Chertkow H, Cummings JL, de Leon M, Feldman H, Ganguli M, Hampel H, Scheltens P, Tierney MC, Whitehouse P, Winblad B (2006) Mild cognitive impairment. Lancet 367:1262-1270

10. Laforce R Jr, Rabinovici GD (2011) Amyloid imaging in the differential diagnosis of dementia: review and potential clinical applications. Alzheimers Res Ther 3:31 
11. Rowe CC, Ng S, Ackermann U, Gong SJ, Pike K, Savage G, Cowie TF, Dickinson KL, Maruff P, Darby D, Smith C, Woodward M, Merory J, Tochon-Danguy H, O'Keefe G, Klunk WE, Mathis CA, Price JC, Masters CL, Villemagne VL (2007) Imaging beta-amyloid burden in aging and dementia. Neurology $68: 1718-1725$

12. Mosconi L, Mistur R, Switalski R, Tsui WH, Glodzik L, Li Y, Pirraglia E, De Santi S, Reisberg B, Wisniewski T, de Leon MJ (2009) FDG-PET changes in brain glucose metabolism from normal cognition to pathologically verified Alzheimer's disease. Eur J Nucl Med Mol Imaging 36:811-822

13. Liu X, Erikson C, Brun A (1996) Cortical synaptic changes and gliosis in normal aging, Alzheimer's disease and frontal lobe degeneration. Dementia 7:128-134

14. Silverman DH, Small GW, Phelps ME (1999) Clinical value of neuroimaging in the diagnosis of dementia. Sensitivity and specificity of regional cerebral metabolic and other parameters for early Identification of Alzheimer's disease. Clin Positron Imaging 2:119-130

15. Foster NL, Heidebrink JL, Clark CM, Jagust WJ, Arnold SE, Barbas NR, DeCarli CS, Turner RS, Koeppe RA, Higdon R, Minoshima S (2007) FDG-PET improves accuracy in distinguishing frontotemporal dementia and Alzheimer's disease. Brain 130:2616-2635

16. Mosconi L, Tsui WH, Herholz K, Pupi A, Drzezga A, Lucignani G, Reiman EM, Holthoff V, Kalbe E, Sorbi S, Diehl-Schmid J, Perneczky R, Clerici F, Caselli R, Beuthien-Baumann B, Kurz A, Minoshima S, de Leon MJ (2008) Multicenter standardized ${ }^{18}$ F-FDG PET diagnosis of mild cognitive impairment, Alzheimer's disease, and other dementias. J Nucl Med 49:390-398

17. Ng S, Villemagne VL, Berlangieri S, Lee ST, Cherk M, Gong SJ, Ackermann U, Saunder T, Tochon-Danguy H, Jones G, Smith C, O'Keefe G, Masters CL, Rowe CC (2007) Visual assessment versus quantitative assessment of ${ }^{11} \mathrm{C}$-PIB PET and ${ }^{18}$ F-FDG PET for detection of Alzheimer's disease. J Nucl Med 48:547-552

18. Chen WP, Samuraki M, Yanase D, Shima K, Takeda N, Ono K, Yoshita M, Nishimura S, Yamada M, Matsunari I (2008) Effect of sample size for normal database on diagnostic performance of brain FDG PET for the detection of Alzheimer's disease using automated image analysis. Nucl Med Commun 29:270-276

19. McMurtray AM, Licht E, Yeo T, Krisztal E, Saul RE, Mendez MF (2008) Positron emission tomography facilitates diagnosis of early-onset Alzheimer's disease. Eur Neurol 59:31-37

20. Silverman DH, Small GW, Chang CY, Lu CS, Kung De Aburto MA, Chen W, Czernin J, Rapoport SI, Pietrini P, Alexander GE, Schapiro MB, Jagust WJ, Hoffman JM, Welsh-Bohmer KA, Alavi A, Clark CM, Salmon E, de Leon MJ, Mielke R, Cummings JL, Kowell AP, Gambhir SS, Hoh CK, Phelps ME (2001) Positron emission tomography in evaluation of dementia: regional brain metabolism and long-term outcome. JAMA 286:2120-2127

21. Panegyres PK, Rogers JM, McCarthy M, Campbell A, Wu JS (2009) Fluorodeoxyglucose-positron emission tomography in the differential diagnosis of early-onset dementia: a prospective, community-based study. BMC Neurol 9:41

22. Jagust W, Reed B, Mungas D, Ellis W, Decarli C (2007) What does fluorodeoxyglucose PET imaging add to a clinical diagnosis of dementia? Neurology 69:871-877

23. Drzezga A, Lautenschlager N, Siebner H, Riemenschneider M, Willoch F, Minoshima S, Schwaiger M, Kurz A (2003) Cerebral metabolic changes accompanying conversion of mild cognitive impairment into Alzheimer's disease: a PET follow-up study. Eur J Nucl Med Mol Imaging 30:1104-1113

24. Choo IH, Ni R, Scholl M, Wall A, Almkvist O, Nordberg A (2013) Combination of ${ }^{18}$ F-FDG PET and cerebrospinal fluid biomarkers as a better predictor of the progression to Alzheimer's disease in mild cognitive impairment patients. J Alzheimers Dis 33:929-939

25. Landau SM, Harvey D, Madison CM, Koeppe RA, Reiman EM, Foster NL, Weiner MW, Jagust WJ (2011) Associations between cognitive, functional, and FDG-PET measures of decline in AD and MCI. Neurobiol Aging 32:1207-1218

26. Ishii K, Soma T, Kono AK, Sofue K, Miyamoto N, Yoshikawa T, Mori E, Murase K (2007) Comparison of regional brain volume and glucose metabolism between patients with mild dementia with Lewy bodies and those with mild Alzheimer's disease. J Nucl Med 48:704-711

27. Rowe CC, Villemagne VL (2013) Brain amyloid imaging. J Nucl Med Technol 41:11-18

28. Johnson KA, Minoshima S, Bohnen NI, Donohoe KJ, Foster NL, Herscovitch P, Karlawish JH, Rowe CC, Carrillo MC, Hartley DM, Hedrick S, Pappas V, Thies WH (2013) Appropriate use criteria for amyloid PET: a report of the Amyloid Imaging Task Force, the Society of Nuclear Medicine and Molecular Imaging, and the Alzheimer's Association. Alzheimers Dement 9:e-1-e-16

29. Rabinovici GD, Rosen HJ, Alkalay A, Kornak J, Furst AJ, Agarwal N, Mormino EC, O’Neil JP, Janabi M, Karydas A, Growdon ME, Jang JY, Huang EJ, Dearmond SJ, Trojanowski JQ, Grinberg LT, Gorno-Tempini ML, Seeley WW, Miller BL, Jagust WJ (2011) Amyloid vs FDG-PET in the differential diagnosis of AD and FTLD. Neurology 77:2034-2042

30. Hardy J, Selkoe DJ (2002) The amyloid hypothesis of Alzheimer's disease: progress and problems on the road to therapeutics. Science 297:353-356

31. Jack CR Jr, Knopman DS, Jagust WJ, Shaw LM, Aisen PS, Weiner MW, Petersen RC, Trojanowski JQ (2010) Hypothetical model of dynamic biomarkers of the Alzheimer's pathological cascade. Lancet Neurol 9:119-128

32. Pontecorvo MJ, Mintun MA (2011) PET amyloid imaging as a tool for early diagnosis and identifying patients at risk for progression to Alzheimer's disease. Alzheimers Res Ther 3:11

33. Forsberg A, Engler H, Almkvist O, Blomquist G, Hagman G, Wall A, Ringheim A, Langstrom B, Nordberg A (2008) PET imaging of amyloid deposition in patients with mild cognitive impairment. Neurobiol Aging 29:1456-1465

34. Förster S, Yousefi BH, Wester HJ, Klupp E, Rominger A, Forstl H, Kurz A, Grimmer T, Drzezga A (2012) Quantitative longitudinal interrelationships between brain metabolism and amyloid deposition during a 2-year follow-up in patients with early Alzheimer's disease. Eur J Nucl Med Mol Imaging 39:1927-1936

35. Mosconi L (2013) Glucose metabolism in normal aging and Alzheimer's disease: methodological and physiological considerations for PET studies. Clin Transl Imaging 1:217-233

36. Shimada H, Shinotoh H, Hirano S, Miyoshi M, Sato K, Tanaka $\mathrm{N}$, Ota $\mathrm{T}$, Fukushi $\mathrm{K}$, Irie $\mathrm{T}$, Ito $\mathrm{H}$, Higuchi M, Kuwabara $\mathrm{S}$, Suhara T (2013) Beta-amyloid in Lewy body disease is related to Alzheimer's disease-like atrophy. Mov Disord 28:169-175

37. Fujishiro H, Iseki E, Higashi S, Kasanuki K, Murayama N, Togo T, Katsuse O, Uchikado H, Aoki N, Kosaka K, Arai H, Sato K (2010) Distribution of cerebral amyloid deposition and its relevance to clinical phenotype in Lewy body dementia. Neurosci Lett 486:19-23

38. Lee VM, Balin BJ, Otvos L Jr, Trojanowski JQ (1991) A68: a major subunit of paired helical filaments and derivatized forms of normal Tau. Science 251:675-678

39. Agdeppa ED, Kepe V, Liu J, Flores-Torres S, Satyamurthy N, Petric A, Cole GM, Small GW, Huang SC, Barrio JR (2001) Binding characteristics of radiofluorinated 6-dialkylamino-2naphthylethylidene derivatives as positron emission tomography 
imaging probes for beta-amyloid plaques in Alzheimer's disease. J Neurosci 21:RC189

40. Small GW, Kepe V, Ercoli LM, Siddarth P, Bookheimer SY, Miller KJ, Lavretsky H, Burggren AC, Cole GM, Vinters HV, Thompson PM, Huang SC, Satyamurthy N, Phelps ME, Barrio JR (2006) PET of brain amyloid and tau in mild cognitive impairment. N Engl J Med 355:2652-2663

41. Ercoli LM, Small GW, Siddarth P, Kepe V, Huang SC, Miller KJ, Lavretsky H, Bookheimer SY, Barrio JR, Silverman DH (2012) Assessment of dementia risk in aging adults using both FDG-PET and FDDNP-PET imaging. Int J Geriatr Psychiatry 27:1017-1027

42. Okello A, Edison P, Archer HA, Turkheimer FE, Kennedy J, Bullock R, Walker Z, Kennedy A, Fox N, Rossor M, Brooks DJ (2009) Microglial activation and amyloid deposition in mild cognitive impairment: a PET study. Neurology 72:56-62

43. Iannaccone S, Cerami C, Alessio M, Garibotto V, Panzacchi A, Olivieri S, Gelsomino G, Moresco RM, Perani D (2013) In vivo microglia activation in very early dementia with Lewy bodies, comparison with Parkinson's disease. Parkinsonism Relat Disord 19:47-52

44. Schuitemaker A, Kropholler MA, Boellaard R, van der Flier WM, Kloet RW, van der Doef TF, Knol DL, Windhorst AD, Luurtsema G, Barkhof F, Jonker C, Lammertsma AA, Scheltens P, van Berckel BN (2013) Microglial activation in Alzheimer's disease: an (R)- $\left[{ }^{11} \mathrm{C}\right] \mathrm{PK} 11195$ positron emission tomography study. Neurobiol Aging 34:128-136

45. Mazere J, Prunier C, Barret O, Guyot M, Hommet C, Guilloteau D, Dartigues JF, Auriacombe S, Fabrigoule C, Allard M (2008) In vivo SPECT imaging of vesicular acetylcholine transporter using $\left[{ }^{123} \mathrm{I}\right]-\mathrm{IBVM}$ in early Alzheimer's disease. Neuroimage 40:280-288

46. Herholz K, Weisenbach S, Zundorf G, Lenz O, Schroder H, Bauer B, Kalbe E, Heiss WD (2004) In vivo study of acetylcholine esterase in basal forebrain, amygdala, and cortex in mild to moderate Alzheimer disease. Neuroimage 21:136-143

47. Shimada H, Hirano S, Shinotoh H, Aotsuka A, Sato K, Tanaka N, Ota T, Asahina M, Fukushi K, Kuwabara S, Hattori T, Suhara $\mathrm{T}$, Irie $\mathrm{T}$ (2009) Mapping of brain acetylcholinesterase alterations in Lewy body disease by PET. Neurology 73:273-278

48. Colloby SJ, Firbank MJ, Pakrasi S, Lloyd JJ, Driver I, McKeith IG, Williams ED, O'Brien JT (2008) A comparison of 99mTcexametazime and ${ }^{123}$ I-FP-CIT SPECT imaging in the differential diagnosis of Alzheimer's disease and dementia with Lewy bodies. Int Psychogeriatr 20:1124-1140

49. Walker Z, Jaros E, Walker RW, Lee L, Costa DC, Livingston G, Ince PG, Perry R, McKeith I, Katona CL (2007) Dementia with Lewy bodies: a comparison of clinical diagnosis, FP-CIT single photon emission computed tomography imaging and autopsy. J Neurol Neurosurg Psychiatry 78:1176-1181

50. Burke JF, Albin RL, Koeppe RA, Giordani B, Kilbourn MR, Gilman S, Frey KA (2011) Assessment of mild dementia with amyloid and dopamine terminal positron emission tomography. Brain 134:1647-1657

51. Ohyama M, Senda M, Ishiwata K, Kitamura S, Mishina M, Ishii K, Toyama H, Oda K, Katayama Y (1999) Preserved benzodiazepine receptors in Alzheimer's disease measured with C-11 flumazenil PET and I-123 iomazenil SPECT in comparison with CBF. Ann Nucl Med 13:309-315

52. Pascual B, Prieto E, Arbizu J, Marti-Climent JM, Penuelas I, Quincoces G, Zarauza R, Pappata S, Masdeu JC (2012) Decreased carbon-11-flumazenil binding in early Alzheimer's disease. Brain 135:2817-2825

53. Catafau AM (2001) Brain SPECT in clinical practice. Part I: perfusion. J Nucl Med 42:259-271
54. Herholz K, Schopphoff H, Schmidt M, Mielke R, Eschner W, Scheidhauer K, Schicha H, Heiss WD, Ebmeier K (2002) Direct comparison of spatially normalized PET and SPECT scans in Alzheimer's disease. J Nucl Med 43:21-26

55. Messa C, Perani D, Lucignani G, Zenorini A, Zito F, Rizzo G, Grassi F, Del Sole A, Franceschi M, Gilardi MC et al (1994) High-resolution technetium-99m-HMPAO SPECT in patients with probable Alzheimer's disease: comparison with fluorine18-FDG PET. J Nucl Med 35:210-216

56. Davie CA (2008) A review of Parkinson's disease. Br Med Bull $86: 109-127$

57. Hughes AJ, Daniel SE, Lees AJ (2001) Improved accuracy of clinical diagnosis of Lewy body Parkinson's disease. Neurology 57:1497-1499

58. Brooks DJ (2010) Imaging approaches to Parkinson disease. J Nucl Med 51:596-609

59. Pavese N, Rivero-Bosch M, Lewis SJ, Whone AL, Brooks DJ (2011) Progression of monoaminergic dysfunction in Parkinson's disease: a longitudinal ${ }^{18} \mathrm{~F}$-dopa PET study. Neuroimage 56:1463-1468

60. Asenbaum S, Pirker W, Angelberger P, Bencsits G, Pruckmayer M, Brücke T (1998) $\left[{ }^{123} \mathrm{I}\right]$ beta-CIT and SPECT in essential tremor and Parkinson's disease. J Neural Transm 105:1213-1228

61. Benamer TS, Patterson J, Grosset DG, Booij J, de Bruin K, van Royen E, Speelman JD, Horstink MH, Sips HJ, Dierckx RA, Versijpt J, Decoo D, Van Der Linden C, Hadley DM, Doder M, Lees AJ, Costa DC, Gacinovic S, Oertel WH, Pogarell O, Hoeffken H, Joseph K, Tatsch K, Schwarz J, Ries V (2000) Accurate differentiation of parkinsonism and essential tremor using visual assessment of $\left[{ }^{123} \mathrm{I}\right]$-FP-CIT SPECT imaging: the $\left[{ }^{123} \mathrm{I}\right]$-FP-CIT study group. Mov Disord 15:503-510

62. Jennings DL, Seibyl JP, Oakes D, Eberly S, Murphy J, Marek K (2004) $\left({ }^{123}\right.$ I) beta-CIT and single-photon emission computed tomographic imaging vs clinical evaluation in Parkinsonian syndrome: unmasking an early diagnosis. Arch Neurol 61:1224-1229

63. Marshall VL, Patterson J, Hadley DM, Grosset KA, Grosset DG (2006) Two-year follow-up in 150 consecutive cases with normal dopamine transporter imaging. Nucl Med Commun 27:933-937

64. Wang L, Zhang Q, Li H, Zhang H (2012) SPECT molecular imaging in Parkinson's disease. J Biomed Biotechnol 2012:412-486

65. Jokinen P, Helenius H, Rauhala E, Bruck A, Eskola O, Rinne JO (2009) Simple ratio analysis of ${ }^{18}$ F-fluorodopa uptake in striatal subregions separates patients with early Parkinson disease from healthy controls. J Nucl Med 50:893-899

66. Lee CS, Samii A, Sossi V, Ruth TJ, Schulzer M, Holden JE, Wudel J, Pal PK, de la Fuente-Fernandez R, Calne DB, Stoessl AJ (2000) In vivo positron emission tomographic evidence for compensatory changes in presynaptic dopaminergic nerve terminals in Parkinson's disease. Ann Neurol 47:493-503

67. Bohnen NI, Albin RL, Koeppe RA, Wernette KA, Kilbourn MR, Minoshima S, Frey KA (2006) Positron emission tomography of monoaminergic vesicular binding in aging and Parkinson disease. J Cereb Blood Flow Metab 26:1198-1212

68. Frey KA, Koeppe RA, Kilbourn MR, Vander Borght TM, Albin RL, Gilman S, Kuhl DE (1996) Presynaptic monoaminergic vesicles in Parkinson's disease and normal aging. Ann Neurol 40:873-884

69. Van Laere K, Varrone A, Booij J, Vander Borght T, Nobili F, Kapucu OL, Walker Z, Nagren K, Tatsch K, Darcourt J (2010) EANM procedure guidelines for brain neurotransmission SPECT/PET using dopamine D2 receptor ligands, version 2. Eur J Nucl Med Mol Imaging 37:434-442 
70. Verstappen CC, Bloem BR, Haaxma CA, Oyen WJ, Horstink MW (2007) Diagnostic value of asymmetric striatal D2 receptor upregulation in Parkinson's disease: an $\left[{ }^{123} \mathrm{I}\right] \mathrm{IBZM}$ and $\left[{ }^{123}\right.$ I]FP-CIT SPECT study. Eur J Nucl Med Mol Imaging 34:502-507

71. Schreckenberger M, Hägele S, Siessmeier T, Buchholz HG, Armbrust-Henrich H, Rösch F, Gründer G, Bartenstein P, Vogt $\mathrm{T}$ (2004) The dopamine D2 receptor ligand ${ }^{18} \mathrm{~F}$-desmethoxyfallypride: an appropriate fluorinated PET tracer for the differential diagnosis of parkinsonism. Eur J Nucl Med Mol Imaging 31:1128-1135

72. Vlaar AM, van Kroonenburgh MJ, Kessels AG, Weber WE (2007) Meta-analysis of the literature on diagnostic accuracy of SPECT in parkinsonian syndromes. BMC Neurol 7:27

73. Eckert T, Barnes A, Dhawan V, Frucht S, Gordon MF, Feigin AS, Eidelberg D (2005) FDG PET in the differential diagnosis of parkinsonian disorders. Neuroimage 26:912-921

74. Eidelberg D (2009) Metabolic brain networks in neurodegenerative disorders: a functional imaging approach. Trends Neurosci 32:548-557

75. Eckert T, Tang C, Eidelberg D (2007) Assessment of the progression of Parkinson's disease: a metabolic network approach. Lancet Neurol 6:926-932

76. Juh R, Kim J, Moon D, Choe B, Suh T (2004) Different metabolic patterns analysis of Parkinsonism on the ${ }^{18}$ F-FDG PET. Eur J Radiol 51:223-233

77. Orimo S, Amino T, Itoh Y, Takahashi A, Kojo T, Uchihara T, Tsuchiya K, Mori F, Wakabayashi K, Takahashi H (2005) Cardiac sympathetic denervation precedes neuronal loss in the sympathetic ganglia in Lewy body disease. Acta Neuropathol 109:583-588

78. Estorch M, Camacho V, Paredes P, Rivera E, Rodriguez-Revuelto A, Flotats A, Kulisevsky J, Carrio I (2008) Cardiac ${ }^{123}$ Imetaiodobenzylguanidine imaging allows early identification of dementia with Lewy bodies during life. Eur J Nucl Med Mol Imaging 35:1636-1641

79. Berding G, Schrader CH, Peschel T, van den Hoff J, Kolbe H, Meyer GJ, Dengler R, Knapp WH (2003) [N-methyl ${ }^{11}$ C]metahydroxyephedrine positron emission tomography in Parkinson's disease and multiple system atrophy. Eur J Nucl Med Mol Imaging 30:127-131

80. Imamura K, Hishikawa N, Sawada M, Nagatsu T, Yoshida M, Hashizume Y (2003) Distribution of major histocompatibility complex class II-positive microglia and cytokine profile of Parkinson's disease brains. Acta Neuropathol 106:518-526

81. Gerhard A, Pavese N, Hotton G, Turkheimer F, Es M, Hammers A, Eggert K, Oertel W, Banati RB, Brooks DJ (2006) In vivo imaging of microglial activation with $\left[{ }^{11} \mathrm{C}\right](\mathrm{R})$-PK11195 PET in idiopathic Parkinson's disease. Neurobiol Dis 21:404-412

82. Gerhard A, Banati RB, Goerres GB, Cagnin A, Myers R, Gunn RN, Turkheimer F, Good CD, Mathias CJ, Quinn N, Schwarz J, Brooks DJ (2003) $\left[{ }^{11} \mathrm{C}\right](\mathrm{R})-\mathrm{PK} 11195$ PET imaging of microglial activation in multiple system atrophy. Neurology 61:686-689

83. Gerhard A, Watts J, Trender-Gerhard I, Turkheimer F, Banati RB, Bhatia K, Brooks DJ (2004) In vivo imaging of microglial activation with $\left[{ }^{11} \mathrm{C}\right](\mathrm{R})$-PK11195 PET in corticobasal degeneration. Mov Disord 19:1221-1226

84. Hughes TA, Ross HF, Musa S, Bhattacherjee S, Nathan RN, Mindham RH, Spokes EG (2000) A 10-year study of the incidence of and factors predicting dementia in Parkinson's disease. Neurology 54:1596-1602

85. Emre M, Aarsland D, Brown R, Burn DJ, Duyckaerts C, Mizuno Y, Broe GA, Cummings J, Dickson DW, Gauthier S, Goldman J, Goetz C, Korczyn A, Lees A, Levy R, Litvan I, McKeith I, Olanow W, Poewe W, Quinn N, Sampaio C, Tolosa E, Dubois B
(2007) Clinical diagnostic criteria for dementia associated with Parkinson's disease. Mov Disord 22:1689-1707 (quiz 1837)

86. Edison P, Rowe CC, Rinne JO, Ng S, Ahmed I, Kemppainen N, Villemagne VL, O'Keefe G, Nagren K, Chaudhury KR, Masters CL, Brooks DJ (2008) Amyloid load in Parkinson's disease dementia and Lewy body dementia measured with $\left[{ }^{11} \mathrm{C}\right] \mathrm{PIB}$ positron emission tomography. J Neurol Neurosurg Psychiatry 79:1331-1338

87. Maetzler W, Reimold M, Liepelt I, Solbach C, Leyhe T, Schweitzer K, Eschweiler GW, Mittelbronn M, Gaenslen A, Uebele M, Reischl G, Gasser T, Machulla HJ, Bares R, Berg D (2008) $\left[{ }^{11} \mathrm{C}\right] \mathrm{PIB}$ binding in Parkinson's disease dementia. Neuroimage 39:1027-1033

88. Kremer B, Goldberg P, Andrew SE, Theilmann J, Telenius H, Zeisler J, Squitieri F, Lin B, Bassett A, Almqvist E et al (1994) A worldwide study of the Huntington's disease mutation. The sensitivity and specificity of measuring CAG repeats. N Engl J Med 330:1401-1406

89. Gusella JF, Wexler NS, Conneally PM, Naylor SL, Anderson MA, Tanzi RE, Watkins PC, Ottina K, Wallace MR, Sakaguchi AY et al (1983) A polymorphic DNA marker genetically linked to Huntington's disease. Nature 306:234-238

90. Bates G (2003) Huntingtin aggregation and toxicity in Huntington's disease. Lancet 361:1642-1644

91. Brinkman RR, Mezei MM, Theilmann J, Almqvist E, Hayden MR (1997) The likelihood of being affected with Huntington disease by a particular age, for a specific CAG size. Am J Hum Genet 60:1202-1210

92. Feigin A, Leenders KL, Moeller JR, Missimer J, Kuenig G, Spetsieris P, Antonini A, Eidelberg D (2001) Metabolic network abnormalities in early Huntington's disease: an $\left[{ }^{18} \mathrm{~F}\right] \mathrm{FDG}$ PET study. J Nucl Med 42:1591-1595

93. Ciarmiello A, Cannella M, Lastoria S, Simonelli M, Frati L, Rubinsztein DC, Squitieri F (2006) Brain white-matter volume loss and glucose hypometabolism precede the clinical symptoms of Huntington's disease. J Nucl Med 47:215-222

94. Squitieri F, Cannella M, Simonelli M, Sassone J, Martino T, Venditti E, Ciammola A, Colonnese C, Frati L, Ciarmiello A (2009) Distinct brain volume changes correlating with clinical stage, disease progression rate, mutation size, and age at onset prediction as early biomarkers of brain atrophy in Huntington's disease. CNS Neurosci Ther 15:1-11

95. Grafton ST, Mazziotta JC, Pahl JJ, St George-Hyslop P, Haines JL, Gusella J, Hoffman JM, Baxter LR, Phelps ME (1992) Serial changes of cerebral glucose metabolism and caudate size in persons at risk for Huntington's disease. Arch Neurol 49:1161-1167

96. Squitieri F, Berardelli A, Nargi E, Castellotti B, Mariotti C, Cannella M, Lavitrano ML, de Grazia U, Gellera C, Ruggieri S (2000) Atypical movement disorders in the early stages of Huntington's disease: clinical and genetic analysis. Clin Genet 58:50-56

97. Ciarmiello A, Giovacchini G, Orobello S, Bruselli L, Elifani F, Squitieri F (2012) ${ }^{18}$ F-FDG PET uptake in the pre-Huntington disease caudate affects the time-to-onset independently of CAG expansion size. Eur J Nucl Med Mol Imaging 39:1030-1036

98. Politis M, Pavese N, Tai YF, Kiferle L, Mason SL, Brooks DJ, Tabrizi SJ, Barker RA, Piccini P (2011) Microglial activation in regions related to cognitive function predicts disease onset in Huntington's disease: a multimodal imaging study. Hum Brain Mapp 32:258-270

99. Andrews TC, Weeks RA, Turjanski N, Gunn RN, Watkins LH, Sahakian B, Hodges JR, Rosser AE, Wood NW, Brooks DJ (1999) Huntington's disease progression. PET and clinical observations. Brain 122:2353-2363 
100. Turjanski N, Weeks R, Dolan R, Harding AE, Brooks DJ (1995) Striatal D1 and D2 receptor binding in patients with Huntington's disease and other choreas. A PET study. Brain 118:689-696

101. Weeks RA, Piccini P, Harding AE, Brooks DJ (1996) Striatal D1 and $\mathrm{D} 2$ dopamine receptor loss in asymptomatic mutation carriers of Huntington's disease. Ann Neurol 40:49-54

102. Holthoff VA, Herholz K, Berthold F, Widemann B, Schröder R, Neubauer I, Heiss WD (1993) In vivo metabolism of childhood posterior fossa tumors and primitive neuroectodermal tumors before and after treatment. Cancer 72:1394-1403

103. Garibotto V, Heinzer S, Vulliemoz S, Guignard R, Wissmeyer M, Seeck M, Lovblad KO, Zaidi H, Ratib O, Vargas MI (2013) Clinical applications of hybrid PET/MRI in neuroimaging. Clin Nucl Med 38:e13-e18 